\section{THE MORPHOLOGY OF BLENDS OF LINEAR AND BRANCHED POLYETHYLENES IN SOLD STATE BY SANS}

G. D. Wignall and J. D. Londono, Oak Ridge National Laboratory,* ak Ridge, Tennessee 37831; R. G. Alamo and L. Mandelkern, lorida State University, Tallahassee, Florida 32306; and F. C. tehling, Exxon Chemical Company, Baytown, Texas 77520

In a previous paper we have shown how small-angle neutron and $x$-ray scattering (SANS, SAXS) can be used to determine the melt compatibility of different polyolefins, including high-density (HD), low-density (LD), and linear low density (LLD) polyethylene. Such blends have attained widespread commercial applications, though the understanding of the mechanical and melt-flow properties of such blends has hitherto been handicapped by the absence of a consensus concerning the degree of mixing of the components, both in the meit and solid states. Recent SANS data indicate that for HDPE/LDPE biends, the melt is homogenous for all compositions after proper accounting for $\mathrm{H} / \mathrm{D}$ isotope effects. In this publication we use complementary SANS, DSC, and SAXS to examine the types of norphologies and the different degrees of phase separation which may arise via crystallization effects on cooling from a homogenous melt.

\section{SAMPLE PREPARATION AND DATA ANALYSIS}

The mixtures were prepared by dissolving deuterated linear polymer (HDPE-D), and branched (LDPE-H or LLDPE-H) protonated polymer in ortho-dichlorobenzene, rapidly quenching into chilled methanol and rressing into discs $-1-\mathrm{mm}$ thick via compression molding. The sample concentrations were (wt\%) 80/20, 70/30, 50/50, 23/77, and 10/90 (HDPE-D/LDPE-H). Absolute SANS data were collected as cescribed previously 1 as a function of the scattering vector $(Q)$ in the. range $0.003<Q=4 \pi \lambda^{-1} \sin \theta<0.04 \AA^{-1}$, where $2 \theta$ is the angle of scatter and $\lambda=4.75 \AA$ is the neutron wavelength. For 2-phase systems, Debye, Bueche (DB), et al. ${ }^{2-4}$ proposed that the cross section has the form:

$$
\frac{d \Sigma}{d \Omega}(Q)=\frac{8 \pi a_{1}^{3} \phi_{1} \phi_{2}[S L D(1)-S L D(2)]^{2}}{\left(1+Q^{2} a_{1}^{2}\right)^{2}}
$$

where $a_{1}$ is a length characterizing the spatial dimensions via an exponential correlation function. ${ }^{2-3}$ The volume fractions are $\phi_{1}$ and $\phi_{2}$, and $S L D(1)$ and (2) are the scattering length densities of the two phases.

\section{RESULTS AND DISCUSSION}

\section{A) Slowly Cooled Blends}

Figure 1 shows typical DB plots for samples with 80/20 and 70/30 wt $\%$ blends of HDPE-D and LDPE-H slowly cooled from the meit at $0.75^{\circ} \mathrm{C} / \mathrm{min}$ and the fits for these (and all other) are reasonably linear. Assuming complete separation of the components (i.e., $\phi_{1}=\phi_{D} ; \phi_{2}=$ $\phi H)$, the cross sections calculated from eq. (1) at $(Q=0)$ are shown in Iable 1 along with the experimental SANS results. The agreement with the DB theory is excellent for blends with high concentrations of linear polymer $(\phi D \geq 0.5)$. SAXS data were also collected on these samples and for predominantly linear blends $(\phi \geq 0.5)$ two "peaks" or modulations are clearly seen in Lorentz-corrected plots $\left(Q^{2} \mathrm{~d} \Sigma / \mathrm{d} \Omega\right.$ vs $Q)$, whereas for the predominantly branched samples oniy one feature is observed. The "peak" positions $\left(Q^{*}\right)$ were converted to length scales representing the lamella spacings or "long periods" $(D=$ $\left.2 \pi / Q^{*}\right)$ and are shown in Table 1 . It is interesting to note that the measured and calculated SANS intensities are in good agreement where two SAXS "peaks" are observed, whereas the calculations overestimate the measured cross sections by a factor $(-3)$ when oniy one feanure is present in the SAXS data. This suggests that in HDPErich blends $(\phi \geq 0.5)$, the components are segregated into separate HDand LDPE lamella stacks, each with its own characteristic spacing. For LDPE-rich blends, there is oniy one long period and this implies : that the components are dispersed in a common lamella stack with

Managed by Martin Marietta Energy Systems. Inc., under contract IE-AC05-84OR21400 for the U. S. Department of Energy. mixed HDPE and LDPE lamellae. The difference between the measured and calculated intensities further imply that the components are not completely separated and there must be some mixing of the two species within each lamella. However, the incorporation of as little as 15-20\% LDPE within the HDPE phase (and vice-versa) woulc be enough to bring the experimental and calculated intensities intc agreement. Thus, HDPE LDPE blends are either completely $\left(\phi \geq 0.5^{\circ}\right.$ or almost completely $(\phi<0.5)$ phase separated into separate HDPE and LDPE lamellae over the whole compositional range after slow cooling from the melt.

\section{B. Rapidly Quenched Blends}

$$
\text { CONF-940813-- } 44
$$

SANS data were also collected on blends of HDPE-D/LDPE-H. quenched from the melt into dry ice/acetone at $-78^{\circ} \mathrm{C}$, though these samples gave qualitativeiy different spectra at the LDPE-rich and HDPE-rich ends of the composition range. For LDPE-rich blends (10/90 and 23/77 wt/\%), a monotonic fall-off is observed as a function of $Q$ and the data approach the $Q^{-2}$ asymptote, as opposed to the $Q^{-4}$ behavior observed for slowiy cooled blends [eq. (1)]. This suggests that the scattering arises from individual molecules. as opposed to separate phases with sharp boundaries. When the data are replotted in the Zimm or Ornstein-Zernicke format $\left[\mathrm{d} \Sigma / \mathrm{d} \Omega^{-1}(Q)\right.$ vs. $Q^{2}$, the $(Q=$ $0)$ ] calculated cross section is close to the measured value from the extrapolated intercept (Fig. 2). The radius of gyration $\left(R_{g}\right)\left(R_{g}=\right.$ $140 \mathrm{~A}$ ) is similar to the molecular dimensions measured in the solid state for HDPE-D/HDPE-H blends. For all blends, SAXS shows oniy one feature in the Lorentz-corrected data indicating that there is a single lamellar stack. Thus, for LDPE-rich blends, the deuterated linear polymer seems to be distributed randomly in the LDPE matrix (i.e., co-crystallized with the branched molecules in the lamellae and randomly mixed in the amorphous regions).

For HIDPE-rich mixtures, the situation is quite different as illustrated in Fig. 3. Data for the 80/20 and 70/30 blends along with the 50/50 sample exhibit several inflexions, which seem to reflect the peak in the HDPE scattering. A component of the scattering from the periodic lamellar structure is always present in the blend data, though if the Dlabeled and protonated molecules are randomly mixed, it normally forms a minor correction to the data. However, if the protonated molecules were preferentially located in the interlamellar amorphous regions, this would enhance the scattering length density contrast between the crystal and amorphous regions and the overail lamellar periodicity would therefore show up much more strongly in the blend cross section. For example, assuming an overall crystallinity index of $-33 \%$ for the $80 / 20$ blend, if the average concentrations in the crystal and amorphous regions were $90 / 10$ and $75 / 25$ respectively, the blend cross section would contain a component of $450 \%(-4.5 x)$ the fully deuterated "blank" cross section, which would cause observable inflections in the slope as observed in Fig. 3. Figure 4 shows the corrected signal after subtracting $5 \times$ the PED SANS cross-section. The Zimm plot is now linear with good agreement between the measured $\left(644 \mathrm{~cm}^{-1}\right)$ and calculated $\left(612 \mathrm{~cm}^{-1}\right)$ cross sections. Thus, for rapidiy quenched blends, the components are extensively cocrystallized, though the branched molecules seem to be preferentially contained in the amorphous regions for predominantly linear mixtures. Experiments are currently in progress to explore the solid state morphology of blends of HD and LDPE as a function of quench rate, and these studies are also being extended to HD/LLDPE systems.

\section{REFERENCES}

1. R. A. Alamo, J. D. Londono, I. Mandelkern, F. C. Stehing, and G. D. Wignall, Macromol. 27, 411 (1994)

2. P. Debye and A. M. Bueche, J. AppL Phys. 20, 518 (1949).

3. P. Debye, H. R. Anderson, and H. Brumberger, J. Appl. Phys. 28. 679 (1957)

4. A. M. Fespiandez, G. D. Wignall, and L. H. Sperling, ACS Advanes sini Chiemistry Series, 211, 1534 (1986).
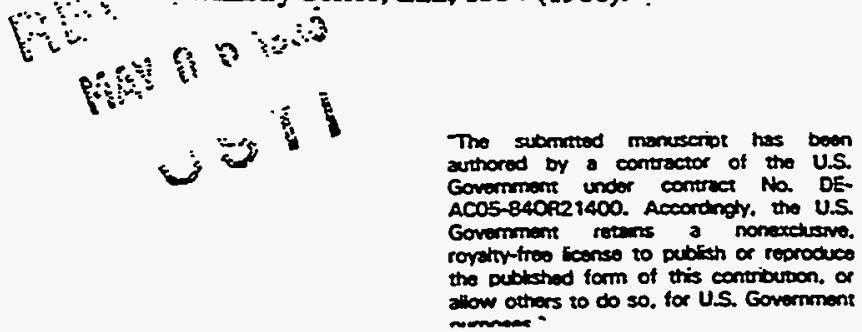
TABLE 1. Measured and Calculated Cross Seetions for HDPE/LDPE Blends Slow Cooled $\left(0.75^{\circ} \mathrm{C} / \mathrm{min}\right)$ From the Melt

\begin{tabular}{|c|c|c|c|c|}
\hline $\begin{array}{l}\text { 31 W(\% } \\
\text { 江DPE) }\end{array}$ & $\begin{array}{l}\text { Correlation } \\
\text { Length }(\dot{A})\end{array}$ & $\begin{array}{l}10^{3} \mathrm{~d} \Sigma / \mathrm{Q} \Omega(Q=0) \\
(\operatorname{expt})\end{array}$ & $\begin{array}{l}\left(\mathrm{cm}^{-1}\right) \\
(\mathrm{calc})\end{array}$ & $\begin{array}{l}\text { Long Period } \\
(\AA)\end{array}$ \\
\hline $\begin{array}{l}120 \\
130 \\
150 \\
77 \\
190\end{array}$ & $\begin{array}{r}63 \\
77 \\
92 \\
114 \\
107\end{array}$ & $\begin{array}{r}7.6 \\
15.5 \\
28.4 \\
15.6 \\
6.9\end{array}$ & $\begin{array}{r}6.9 \\
16.6 \\
34.3 \\
45.0 \\
19.1\end{array}$ & $\begin{array}{c}299 / 125 \\
292 / 125 \\
285 / 114 \\
180 \\
139\end{array}$ \\
\hline
\end{tabular}
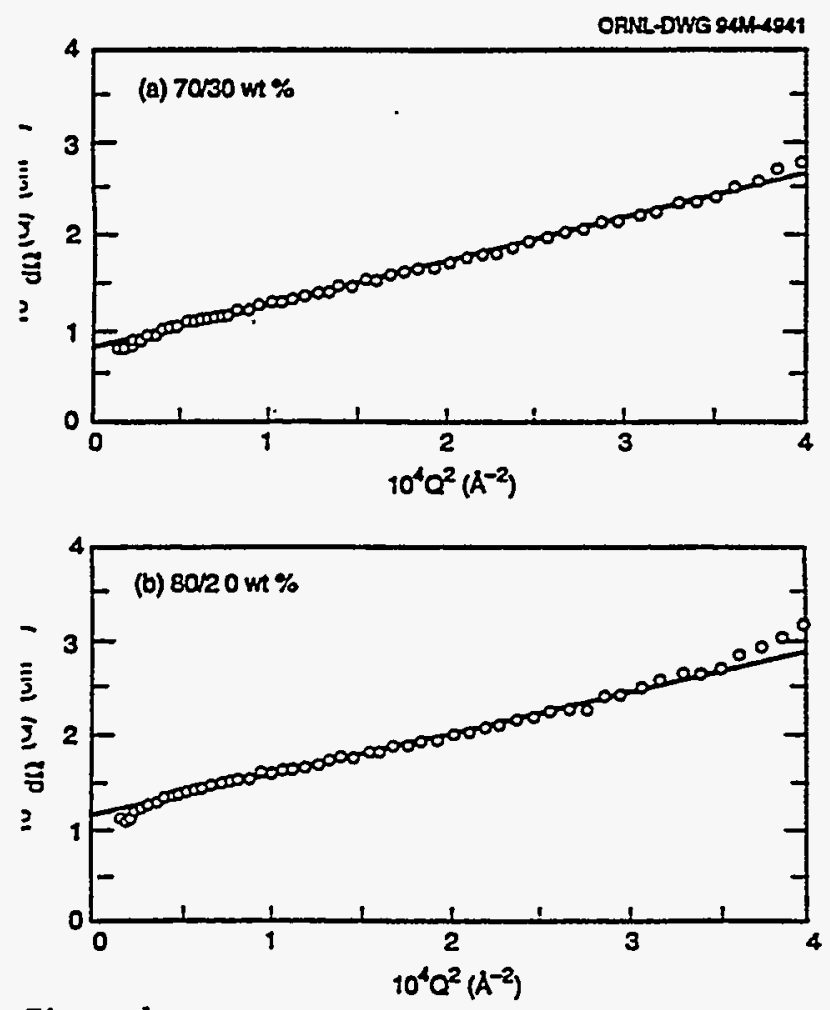

Eigure 1

Debye-Eueche Plots for (a) 70/30 and (b) 80/20 wt \% Blends of HDPE-D and LDPE-H Slow Cooled from Melt $0.75^{\circ} \mathrm{C} / \mathrm{min}$
MASTER

DISTRIEUTION OF THIS DOCUMENT IS UALUMITED



Figure 2

$\frac{d E}{d \Omega}(a)$ vs $Q^{2}$ for 10990 Sample of HDPE-DRDPE-H .

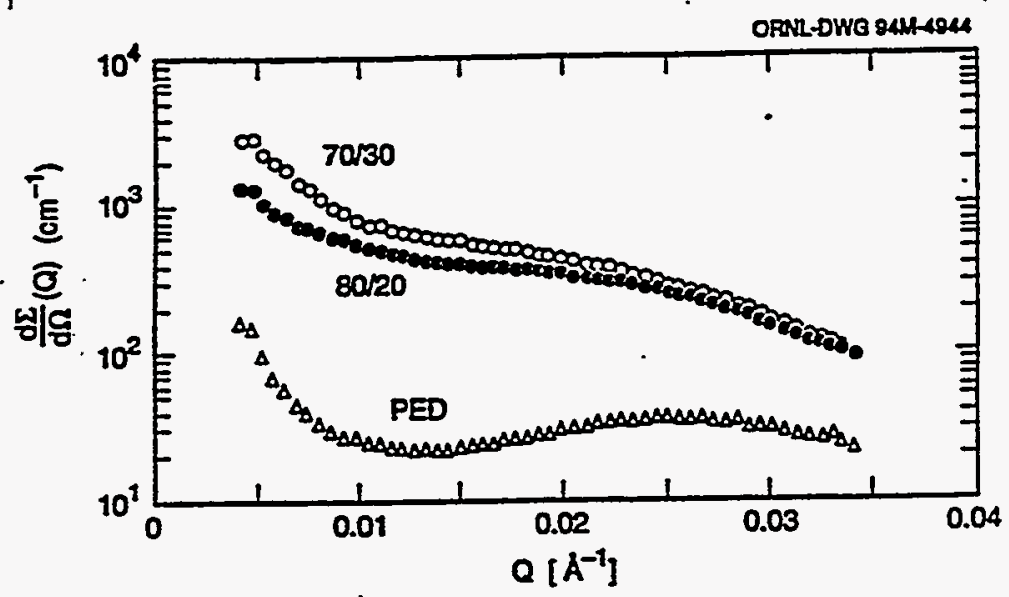

Figure 3

$\frac{d \Sigma}{d \Omega}(Q)$ vs $Q$ for PED and PED-RICH Blends of HDPE-DRDPE.H

ORML-DWG 94M-4943



Figure 4

$\frac{d \Sigma^{-1}}{d \Omega}(Q)$ vs $Q^{2}$ for Rapldly Quenched 80/20 Sample of HDPE-DLDPE-H after Background Correction Based on the Assumption that LDPE 


\section{DISCLAIMER}

This report was prepared as an account of work sponsored by an agency of the United States Government. Neither the United States. Government nor any agency thereof, nor any of their employees, makes any warranty, express or implied, or assumes any legal liability or responsibility for the accuracy, completeness, or usefulness of any information, apparatus, product, or process disclosed, or represents that its use would not infringe privately owned rights. Reference herein to any specific commercial product, process, or service by trade name, trademark, manufacturer, or otherwise does not necessarily constitute or imply its endorsement, recommendation, or favoring by the United States Government or any agency thereof. The views and opinions of authors expressed herein do not necessarily state or refiect those of the United States Government or any agency thereof. 


\section{DISCLAMMER}

Portions of this document may be illegible in electronic image products. Images are produced from the best available original document. 